\section{AL-AZHAR Dental Journal}

F $\quad \mathrm{O} \quad \mathrm{r}$

\title{
Digital Occlusal Load Analysis in Dental Arches Restored with Single Implant Supported Restoration Using Two Occlusal Schemes. (T-Scan in-vivo study)
}

\author{
Sara M. Zoghly ${ }^{1 *}$, Mona H. Mandour ${ }^{2}$, Walaa O. El-Mekkawi ${ }^{3}$
}

Codex : 05/21.07
azhardentj@azhar.edu.eg
http://adjg.journals.ekb.eg

DOI: $10.21608 /$ adjg.2021.29103.1250

Restorative Dentistry

(Removable Prosthodontics, Fixed

Prosthodontics, Endodontics, Dental Biomaterials, Operative Dentistry)

\section{KEYWORDS}

Implant supported,

Occlusal load,

T-Scan, Occlusal design.

\begin{abstract}
Purpose: This study was designed to evaluate the effect of the size of occlusal contact areas of single implant supported restoration on occlusal load distribution on adjacent premolars using a digital occlusal analyzer (T-Scan). Material and Methods: Twenty four patients with missed lower first molar were received delayed dental implants, where they divided into 2 main groups according to the presence or absence of adjacent lower second molar $(n=12)$. Group (I): Patients with missing mandibular first molar with the presence of adjacent second molar and premolar teeth,while group (II): Patients with missing mandibular first molar tooth with the presence of adjacent premolars and absence of adjacent distal molars. Two occlusal schemes were followed during superstructure construction, dividing each group into two subgroups, $(n=6)$. Patients were evaluated for occlusal load distribution before and after cementation of the crown, and after 3 and 6 months using T-scan system (9.1). Results: Regarding second premolar; the occlusal load distribution $\%$ in the different groups was statistically insignificant. Regarding first premolar; occlusal scheme 1 in both groups showed statistically significantly higher median occlusal load distribution $\%$ on the lower first premolar than occlusal scheme 2 in both groups. Conclusion: The size of occlusal contact area of the implant supported crown is an important factor affecting occlusal load distribution on adjacent premolars. Decreasing the size of occlusal contact area of the implant supported crown will increase the force on adjacent premolars.
\end{abstract}

- Paper extracted from PHD thesis titled "Digital Occlusal Load Analysis in Dental Arches Restored with Single Implant Supported Restoration Using Two Occlusal Schemes".

1. Assistant lecturer of Crowns and Bridges, Faculty of Dental Medicine for Girls, Al-Azhar University, Cairo, Egypt.

2. Professor of Crowns and Bridges, Faculty of Dental Medicine for Girls, Al-Azhar University, Cairo, Egypt.

3. Lecturer of Crowns and Bridges, Faculty of Dental Medicine for Girls, Al-Azhar University, Cairo, Egypt.

* Corresponding author email: saratamimi66@yahoo.com 


\section{INTRODUCTION}

Restoration of lost teeth with artificial prostheses has undergone a lot of changes throughout the years. A lot of treatments are present including removable partial dentures, complete dentures, fixed partial dentures and over dentures. The development of dental implants is considered a breakthrough for replacement of missing teeth as it ensures restoration of natural teeth with optimum esthetic. However, it was reported that there was a lot of failed implants which increased with the increased number of implant cases leading to an introspection of the various causes of this failure ${ }^{(1)}$.

The treatment planning of implant supported fixed dental prostheses depends to a great extent on the knowledge and experience of the prosthetic dentists. Furthermore, it should be taken into consideration that a normal tooth has a supporting periodontal ligament that minimizes the loads falling to the supporting alveolar bone meanwhile implant fixtures do not have this type of support. Thus, the design of the occlusal surface should be made that minimizes these forces and allows the implant-supported prosthesis to work in harmony with the remaining oral structures. Mechanical stresses and strain from the oral musculature and occlusion and the increased loss of bone surrounding dental implants could be prevented by following the implant-protected occlusion design. This can be achieved by making the dimentions of the occlusal table of the crown less than that of the corresponding natural tooth, increasing the surface area of implants and improving the direction of the falling force. Minimizing overload on the crown and along the interface between fixed implant and surrounding bone, keeps the forces falling on the implant within the physiological limits of normal occlusion ${ }^{(2)}$.

A computerized occlusal analysis software, T-scan system (9.1), can measure tooth contact, relative force and timing of occlusion using flexible, pressure-sensitive sensors. The system recorded a scan while the patient bite down firmly on the sensor on their back teeth. The recorded scan is displayed on the screen of a computer as 2D or 3D force view that can be analyzed. The investigation of occlusal forces and occlusal interferences can be found from the recorded occlusal information ${ }^{(3)}$.

The present study was performed to assess the effect of the size of occlusal contact areas of single implant supported restoration on occlusal load distribution on adjacent premolars using a digital occlusal analyzer (T-Scan).

\section{MATERIAL AND METHODS}

Twenty-four patients with missed lower first molar were included in this study, where they received delayed dental implants.Selected patients were divided into 2 main groups according to the presence or absence of adjacent lower second molar $(\mathrm{n}=12)$. Group (I): Patients with missing mandibular first molar with the presence of adjacent second molar and premolar teeth, (Intermediate missing cases). Group (II): Patients with missing mandibular first molar tooth with the presence of adjacent premolars and absence of adjacent distal molars, (Unilateral free end cases). Two occlusal schemes were followed during superstructure construction, dividing each group into two subgroups. Subgroup (A) (occlusal scheme1): Implant supported fixed dental prosthesis with the occlusal contact area of the crown smaller than the occlusal contact area of adjacent second premolar. Subgroup (B) (occlusal scheme2): Implant supported fixed dental prosthesis with occlusal contact area of the crown larger than the occlusal contact area of adjacent second premolar. A written consent was obtained from each patient after explaining the study as well as giving information about the treatment and follow up appointments before the initiation of any procedure, according to the guidelines of the research ethics committee in the Faculty of Dental Medicine, for Girls, Al-Azhar University.

Prior to the surgical procedure, medical evaluation was obtained, ensuring the inclusion of only medically free patients. Diagnosis was 
done clinically and radiographically. Preoperative periapical radiograph as well as cone beam computed tomography scan (CBCT) were obtained for each patient.

Clinical evaluation of the mesiodistal space, buccolingual space and occluso-gingival space was done with the help of study casts and CBCT. Implants with appropriate diameter and length were selected for each case according to the buccolingual width of bone (minimum $1 \mathrm{~mm}$ of bone was left buccally and lingually), the mesiodistal width of bone (minimum $2 \mathrm{~mm}$ of bone was left between implant and adjacent teeth) and the length of the implant was selected according to the available bone length and proximity to adjacent vital structures (minimum $2 \mathrm{~mm}$ of bone was left between implant and inferior alveolar canal).

\section{Surgical procedures:}

A full thickness flap was incised, the edges of tissues were pushed aside to expose the bone. After reflecting the soft tissue, precision drills were used to place hole inside the bone, at a regular speed to avoid bone necrosis, then this hole was enlarged gradually by using successively wider drills. The implant was placed into the hole with a torque controlled wrench at the exact torque (Fig.1). A cover screw was placed to seal the implant orifice, the gingiva was adapted around the entire implant and then the flap was closed with interrupted sutures.

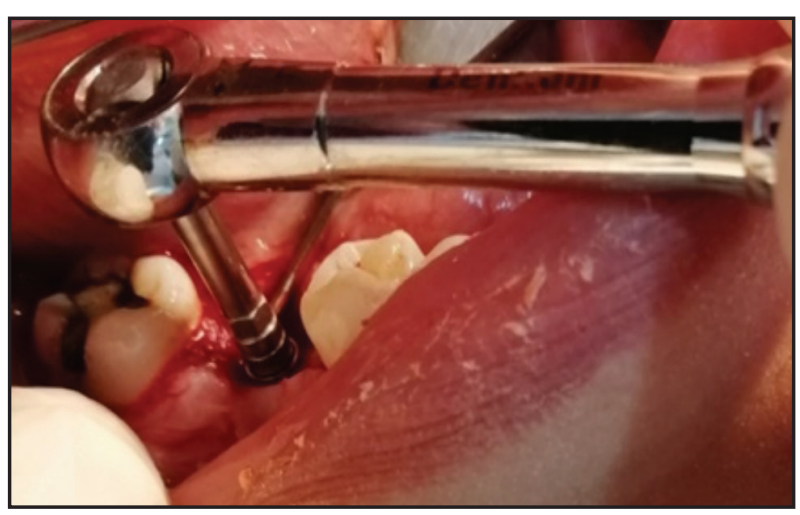

Figure (1): Screwing the implant into place.
Postoperative periapical radiograph was taken to check implant position, the support of the surrounding alveolar bone and determine changes over time. Postoperative instructions and healing time for an implant included cold packs regulated following surgical procedure, and patients were told to proceed with the admission of antibiotics and analgesics whenever regarded fundamental. Also, $0.12 \%$ chlorhexidine solution was described to be utilized two times every day for 7 days. Stitches were removed following 7 days. Three to six months of integrating time was allowed before fabrication of the crowns. A subsequent surgical procedure was made to put a healing cap.

\section{Impression technique:}

At first, the healing abutments were removed, then the square implant level impression transfers were screwed to the implants in the patients' mouth. The trays were perforated in the regions where the implants were placed to provide access for the transfer copings. Heavy consistency addition silicon impression material (LASCOD Spa - Via Longo, Florence - Italy.) was loaded inside the perforated trays and light consistency addition impression material was syringed around the impression copings to cover it completely. Implant analogues were screwed into the implant level impression transfers. Impressions of the opposing upper arch were taken using addition silicon impression material. Impressions of both arches were then poured with type IV dental stone (Elite Rock, Zemack S.P.A.-via Bovazecchino, Italy) to create a model.

\section{Laboratory procedures:}

To obtain a three-dimensional image for each case on the computer screen, each cast was fixed to the tray of the scanner using specific clay. Then the cast with implant abutment was sprayed using light reflecting powder to be scanned using ScanBox scanner (Smart optics ScanBox Gmbh, Germany) for taking 3D optical impression. A digital impression was captured for the cast with implant 
abutment. The articulator (Derby articulator, Asa Dental S.P.A. Italy) with casts was fixed to the scanner to take an optical impression of the casts in occlusion. Then the captured pictures were saved in the occlusion catalogue of the software.

\section{Designing the restoration:}

The software calculated a virtual model from the scanned pictures which was ready for identification of the finish line margin of the implant abutment. The occlusal table was designed to be narrower than the occlusal table of the lower six and the cusp inclines was decreased in height (The contra lateral first molar and adjacent teeth were used as a guide). The software calculated the occlusal contact areas (width and length) of the lower second premolar adjacent to the abutment of the implant. The size of the occlusal contact area of the superstructure was calculated and checked by the software by measuring the width and length of the marked occlusal contact area. For subgroup (A) in groups I and II: The occlusal contact areas of the crown were made smaller than the occlusal contact areas of adjacent second premolar. For subgroup (B) in groups I and II: The occlusal contact areas of the crown were made larger than the occlusal contact areas of adjacent second premolar. The primary occlusal contact was placed over the central fossa to be centralized over the implant. No marginal ridge contacts were present to prevent cantilever effects and bending moments. A secondary occlusal contact was kept within $1 \mathrm{~mm}$ of the boundaries of the crown away from marginal ridges to decrease moment forces.

\section{Fabrication of Zirconia crowns:}

After finishing the design phase, multi layered Katana Zirconia disc (Kurary Noritake Dental Inc. Japan) was placed in the Roland milling machine (Roland DG Corporation. JAPAN) and the preview window was activated to start the milling process. After milling, crowns were placed on the ceramic sintering tray and then placed in the HTC furnace (High temperature furnace with program control unit) (Sirona dental system GMBH. Fabrikstra B 31, D64625.Bensheim.Germany) to be sintered according to manufacturer's instructions. After sintering, Zirconia crowns were stained and glazed using FC Paste Stain Glaze or Clear Glaze according to the shade color of each patient. All crowns were seated on their corresponding abutments on the casts and checked for complete seating using a magnifying lens. Each crown was checked in the patient's mouth for proper marginal seal, contour, proper contact area and proper occlusion according to each design.

\section{Cementation procedure:}

A temporary luting agent (Dentotemp Itena, America) was used to cement the crowns. A dainty layer of the cement was applied to the center of the intaglio surface of the crowns. The crown was immediately seated and hold set up. Excess cement was removed within 90-120seconds while cement is in the rubbery stage. The cement was finally set between 3-4 minutes. Post cementation peri-apical radiograph was taken to detect any excess cement.

\section{Occlusal load analysis:}

A computerized occlusal analysis system, T-scan (9.1), was used for assessment of occlusal load distribution. Patients were evaluated for occlusal load distribution before cementation of the crown, just immediately after cementation, after 3 months and after 6 months of implant loading.

\section{Statistical analysis:}

Numerical data were explored for normality by checking the distribution of data and victimization tests of normality (KolmogorovSmirnov and Shapiro-Wilk tests). Occlusal load distribution \% showed non-normal (nonparametric) distribution, so that they were conferred as median and range values. Kruskal-Wallis test, Friedman's test, Fisher's Exact test and Dunn's test were employed in this study. Qualitative data were conferred as frequencies and percentages. The significance level was set at $\mathrm{P} \leq 0.05$. 


\section{RESULTS}

\section{1- Comparison between Occlusal load distribu- tion (\%) among the groups:}

\section{- Regarding second premolar:}

Before cementation; Pair-wise comparisons between the groups revealed that there was no statistically significant difference between Group I - Occlusal scheme 2, Group II -Occlusal scheme 1 and Group II - Occlusal scheme 2; all showed statistically significantly higher median occlusal load distribution \% than Group I-Occlusal scheme 1. On the other hand, there was no statistically significant difference between the occlusal load distribution \% in the different groups after cementation, after 3 as well as 6 months. (Table 1)

\section{- Regarding first premolar:}

Before cementation, Group II - Occlusal scheme 2 showed the statistically significantly highest median occlusal load distribution \%. Group II Occlusal scheme 1 showed statistically significantly lower median load distribution $\%$. There was no statistically significant difference between Group I - Occlusal scheme 1 and Group I - Occlusal scheme 2; both showed the statistically significantly lowest median occlusal load distribution \%. While, after cementation, there was no statistically significant difference between Group I - Occlusal scheme 1, Group I-Occlusal scheme 2 and Group II - Occlusal scheme 2 ; all showed statistically significantly lower median occlusal load distribution \% than Group II Occlusal scheme 1.

After 3 months; there was no statistically significant difference between Group I - Occlusal scheme 1 and Group II - Occlusal scheme 1; both showed the statistically significantly highest median occlusal load distribution $\%$. There was no statistically significant difference between Group IOcclusal scheme 2 and Group II - Occlusal scheme 2; both showed the statistically significantly lowest median occlusal load distribution \%. However, after 6 months; there was no statistically significant difference between occlusal load distribution $\%$ in the different groups $(P$-value $=0.609$, Effect size $=$ 0.059). (Table 2)

Table (1): Occlusal load distribution \% on second premolar in the different groups.

\begin{tabular}{|c|c|c|c|c|c|c|c|c|c|c|}
\hline \multirow[t]{2}{*}{ Time } & \multicolumn{2}{|c|}{$\begin{array}{c}\text { Group I - Occlusal } \\
\text { scheme } 1 \\
(n=6)\end{array}$} & \multicolumn{2}{|c|}{$\begin{array}{c}\text { Group I - Occlusal } \\
\text { scheme } 2 \\
(n=6)\end{array}$} & \multicolumn{2}{|c|}{$\begin{array}{c}\text { Group II - Occlusal } \\
\text { scheme } 1 \\
(n=6)\end{array}$} & \multicolumn{2}{|c|}{$\begin{array}{c}\text { Group II - Occlusal } \\
\text { scheme } 2 \\
(n=6)\end{array}$} & \multirow[t]{2}{*}{$P$-value } & \multirow{2}{*}{$\begin{array}{l}\text { Effect } \\
\text { size (Eto } \\
\text { Squared }\end{array}$} \\
\hline & Median & Range & Median & Range & Median & Range & Median & Range & & \\
\hline $\begin{array}{c}\text { Before } \\
\text { cementation }\end{array}$ & $1.65^{\mathrm{B}}$ & $0-3$ & $10.5^{\mathrm{A}}$ & $0.3-14.2$ & $8.1^{\mathrm{A}}$ & $0.7-20$ & $8.4^{\mathrm{A}}$ & $3.2-9.4$ & $0.037 *$ & 0.273 \\
\hline $\begin{array}{c}\text { After } \\
\text { cementation }\end{array}$ & 5.25 & $4.4-12$ & 8.15 & $1.1-14.5$ & 7.9 & $0.9-14$ & 17.6 & $5.8-21$ & 0.153 & 0.113 \\
\hline 3 months & 5.9 & $5-8.1$ & 8.05 & $3.4-9.3$ & 13.2 & $2.7-19.2$ & 2.9 & $1.9-31$ & 0.076 & 0.194 \\
\hline 6 months & 4.75 & $1.4-8.8$ & 7.3 & $6.3-10.9$ & 11 & $2.03-26.7$ & 8.9 & $4.7-10.6$ & 0.339 & 0.018 \\
\hline
\end{tabular}

$* P \leq 0.05$, Superscripts in the same row are significantly different 
Table (2): Occlusal load distribution \% on first premolar in the different groups.

\begin{tabular}{|c|c|c|c|c|c|c|c|c|c|c|}
\hline \multirow[t]{2}{*}{ Time } & \multicolumn{2}{|c|}{$\begin{array}{l}\text { Group I - Occlusal } \\
\text { scheme } 1 \\
(n=6)\end{array}$} & \multicolumn{2}{|c|}{$\begin{array}{c}\text { Group I - Occlusal } \\
\text { scheme } 2 \\
(n=6)\end{array}$} & \multicolumn{2}{|c|}{$\begin{array}{l}\text { Group II - Occlusal } \\
\text { scheme } 1 \\
(n=6)\end{array}$} & \multicolumn{2}{|c|}{$\begin{array}{c}\text { Group II - Occlusal } \\
\text { scheme } 2 \\
(n=6)\end{array}$} & \multirow[t]{2}{*}{$P$-value } & \multirow[t]{2}{*}{$\begin{array}{c}\text { Effect } \\
\text { size (Eta } \\
\text { Squared) }\end{array}$} \\
\hline & Median & Range & Median & Range & Median & Range & Median & Range & & \\
\hline $\begin{array}{c}\text { Before } \\
\text { cementation }\end{array}$ & $5.05^{\mathrm{C}}$ & $0.8-9$ & $5.2^{\mathrm{C}}$ & $4-7.6$ & $22.05^{\text {B }}$ & $16-28$ & $38.25^{\mathrm{A}}$ & $13.5-50.5$ & $0.001 *$ & 0.726 \\
\hline $\begin{array}{c}\text { After } \\
\text { cementation }\end{array}$ & $7.5^{\mathrm{B}}$ & $3.15-9.4$ & $4.3^{\text {в }}$ & $2.9-6.3$ & $13.95^{\mathrm{A}}$ & $10.2-25.7$ & $3.85^{\mathrm{B}}$ & $2.2-8$ & $0.002 *$ & 0.584 \\
\hline 3 months & $8.3^{\mathrm{A}}$ & $6.2-10.1$ & $3.75^{\mathrm{B}}$ & $1.1-8.2$ & $11.35^{\mathrm{A}}$ & $7.8-19.9$ & $3.65^{\text {в }}$ & $1.1-11.5$ & $0.022 *$ & 0.332 \\
\hline 6 months & 8.05 & $6.9-15.8$ & 8 & $4.6-9.8$ & 6.8 & $2.7-16.6$ & 7.53 & $2.9-9.8$ & 0.609 & 0.059 \\
\hline
\end{tabular}

$* P \leq 0.05$, superscripts in the same row are significantly different

\section{2- Comparison between occlusal load distribution} $(\%)$ in different time periods

- Group I - Occlusal scheme 1: As regard second and first premolars; there was no statistically significant change in occlusal load distribution \% by time $(P$-value $=0.073$, Effect size $=0.387)$ and $(P$-value $=0.284$, Effect size $=0.211)$, respectively.

- Group I - Occlusal scheme 2: As regard second premolar; there was no statistically significant change in occlusal load distribution $\%$ by time $(P$-value $=0.241$, Effect size $=$ 0.233). While for first premolar; there was no statistically significant change in median occlusal load distribution \% after cementation as well as after 3 months. From 3 to 6 months; there was a statistically significant increase in median occlusal load distribution $\%$.

- Group II - Occlusal scheme 1: As regard second premolar; there was no statistically significant change in occlusal load distribution $\%$ by time $(P$-value $=0.284$, Effect size $=$ $0.211)$. While for first premolar; there was a statistically significant decrease in median occlusal load distribution $\%$ after cementation followed by non-statistically significant change after 3 months. From 3 to 6 months; there was a statistically significant decrease in median occlusal load distribution $\%$.

- Group II - Occlusal scheme 2: As regards to second premolar; there was no statistically significant change in occlusal load distribution $\%$ by time $(P$-value $=0.133$, Effect size $=$ 0.311). While for first premolar; there was a statistically significant decrease in median occlusal load distribution \% after cementation followed by non-statistically significant change after 3 months as well as from 3 to 6 months.

\section{DISCUSSION}

There are several complications of dental implant prosthesis including failure of the fixture osseointegration, loosening of the screw, mechanical failure, shipping of ceramic veneer, resorption of bone, loss of osseointegration, gingivitis and increasing load on adjacent teeth ${ }^{(4)}$. Upkeep of the pulpal and periapical wellbeing of neighboring teeth is of imperative significance to forestall further treatment needs of patients getting dental and implant treatment. While, there has been broad 
research on implants and their restoration, there has been constrained investigation of their impacts on neighboring teeth ${ }^{(5)}$.

The present study evaluated the effect of 2 occlusal schemes of the occlusal surface of the implant supported crowns replacing mandibular first molar on the occlusal load distribution on adjacent premolars. The occlusal load distribution was measured using a digital Tek-scan system, (9.1). Intra oral scans were taken before and after cementation as well as three and six months after cementation using a digital occlusal sensor. The sensor of Tek-Scan measures all the load applied in $\mathrm{N} / \mathrm{cm}^{2}$ and expressed as a percentage of that value to the corresponding regions. Information recorded brought about acontinuous stress map of occlusal load distribution over the time. The information are shown in 2D and 3D force view graphics by the T-scan program ${ }^{(6,7)}$.

The percentage of total occlusal load distribution was evaluated immediately before cementation, after crown cementation and at three and six months after delivery. The selection of follow up duration is in accordance with a previous study which reported that in half of the examined patients, the occlusion of fixed prostheses changed inside year and a half after insertion ${ }^{(8)}$. The greater part of the progressions occured within the initial a half year after prostheses cementation.

There was no statistically significant difference between occlusal load distribution on the second premolar in different groups. However, there was a statistical significant difference between occlusal load before cementation and after 6 months follow up period in each group, table (1). In group I, occlusal scheme1 (Bounded implant with small occlusal contact area), the occlusal load on lower second premolar increased from (1.65\% to $4.8 \%$ ), while in group II, occlusal scheme1 (Free end implant with small occlusal contact area), the median occlusal load on lower second premolar increased from ( $8.1 \%$ to $11 \%)$. Also, in group II occlusal scheme
2 (free end implants with large occlusal contacts); occlusal load slightly increased $(8.4 \%$ to $8.9 \%$ ). On the other hand, in group I occlusal scheme 2 (bounded implants with large occlusal contact area), occlusal load on lower second premolar decreased from $(10.5 \%$ to $7.3 \%)$.

These results suggested that decreasing the size of occlusal contact area of the crown will increase the load on the adjacent lower second premolar, while increasing the size of occlusal contact area of the crown will not affect the load on the adjacent lower second premolar which was in agreement with a previous study which suggested that there was a relationship between the occlusal contact area of the implant replacing lower first molar and periodontal mechanosensitive thresholds of adjacent premolars in implants without a distal adjacent teeth. Increased threshold was associated with the small occlusal contact area. So, the size of occlusal contact area of the crown should be considered for long-term upkeep of the function of oromandibular system, including preventing damage of adjacent premolars. On the other hand, in bounded cases, single implant prosthesis had insignificant effect on occlusal force distribution on adjacent premolars because the equalization of the occlusal load and occlusal area had already been done by the adjacent teeth ${ }^{(9)}$.

Occlusal load on the first premolar was significantly affected by different occlusal designs. Group II occlusal scheme1 showed higher median occlusal load distribution $\%$ on first premolar than other groups after cementation. After 3 months, scheme 1 occlusal contact in both groups showed higher median occlusal load distribution on the lower first premolar \% than other groups. After six months there was no significant difference between different groups. This conclusion was in aggrement with a previous study which concluded that single posterior implant supported restorations, designed according to implant protective occlusion, significantly increased the total load in the restored 
sextants ${ }^{(7)}$. In addition, the total occlusal pressure decreased in the contralateral sextant. These results come in agreement with the increased occlusal load on adjacent premolars in the present study.

Also this result could be explained by other who concluded that the intensity of occlusal contacts of the crowns in the posterior regions gradually increased after prosthesis insertion ${ }^{(6)}$.

In the present study there was no significant difference in occlusal load distribution on lower second premolar during different time periods in all the groups. These results come in agreement with a previous study which found that the occlusal force distribution on the implant supported restoration was larger than adjacent teeth.However, in the early periods of chewing, the force on the implant and adjacent natural tooth was equalized by leaving a space between the crown restoration and the adjacent tooth. While during strong chewing, the force on the implant and adjacent tooth was comparable with no gap between them. So, the force on the implant and adjacent tooth had finally become comparable, but if the gap is more than 20um, the load distribution on the adjacent tooth would be more than that on the implant ${ }^{(10)}$.

Results of this study showed that there was no significant difference in occlusal load distribution on lower first premolar in group I occlusal scheme1 in all time periods, and in group I occlusal scheme2 before cementation, after cementation and after 3 months. However, there was a significant increase in occlusal load on lower first premolar from 3 to 6 months. This increase in load may be due to continuous eruption of natural teeth adjacent to the implant which could result in infra-occlusion of implant supported prosthesis in the long term ${ }^{(11)}$.

In group II occlusal scheme1, there was a gradual decrease in occlusal load on the lower first premolar during different time periods. In group II occlusal scheme2, there was a significant decrease in occlusal load on the lower first premolar after cementation only and there was no significant difference after three and six months. So, increasing the occlusal contact area will decrease the load on lower first premolar and lead to stable load distribution during different time periods. While decreasing the occlusal contact area in free end implant prosthesis will lead to continuous and gradual decrease in occlusal load on lower first premolar regarding time periods. This may be due to that the more posterior implant decreases the force on the anterior teeth ${ }^{(7)}$ and it was also apparent that the absence of the second molar leads to pressure focus in the distal district of the mandible and so, decreasing the load on the more anterior dentition. The presence of a second molar proximal contact is significant in limiting the stresses around the implants supporting crowns, independent of the occlusal loading condition ${ }^{(12)}$.

\section{CONCLUSIONS}

1. The size of occlusal contact area of the implantsupported crowns is an important factor affecting occlusal load distribution on adjacent premolars. Decreasing the size of occlusal contact area of the implant-supported crowns will increase the load on adjacent premolars.

2. Mandibular first premolar is strongly affected by the occlusal design of posterior single implant supported prosthesis within the first six months of superstructure cementation.

\section{REFERENCES}

1. Jacob SA, Nandini VV, Nayar S, Gopalakrishnan A. Occlusal principles and considerations for the osseointegrated prosthesis. J Dent Med Sci. 2013; 3:47-54.

2. Paliwal S, Saxena D, Mittal R, Chaudhary SH. Occlusal Principles and Considerations for Implants: An Overview. JADE 2014; 1: 17-21.

3. Agbaje JO, Casteele EVD, Salem AS, Anumendem D, Shaheen E, Sun Y, et al. Assessment of occlusion with the T-Scan system in patients undergoing orthognathic surgery.Sci Rep. 2017;13:53-6. 
4. Albrektsson T, Buser D, Sennerby L. Crestal bone loss and oral implants. Clin Implant Dent Relat Res.2012; 14:783-91.

5. Duqum I, Barker S, Marshall E, Wang R, Preisser J S, Khan A. The effect of single tooth implant restorations on the survival, morbidity, pulpal, and periapical health of adjacent teeth: A chart review.Clin Implant Dent Relat Res. 2018; 20:479-82.

6. Madani AS, Nakhaei M, Alami M, Haghi HR, Moazzami SM. Post-insertion Posterior Single-implant Occlusion Changes at Different Intervals: A T-Scan Computerized Occlusal Analysis. J Contemp DentPract.2017; 18:927-32.

7. Roque MA, Gallucci GO, Lee SJ. Occlusal Pressure Redistribution with Single Implant Restorations. J Prosthodont 2017; 26:275-9.

8. Luo Q, Ding Q, Zhang L and Xie Q. Analyzing the occlusion variation of single posterior implant supported fixed prostheses by using the T-scan system: A prospective 3-year follow-up study. J Prosthet Dent 2020; 123:79-84.
9. Terauchi R, Arai K, Tanaka M, Kawazoe T, Baba Sh. Effect of difference in occlusal contact area of mandibular free-end edentulous area implants on periodontal mechanosensitive threshold of adjacent premolars. Springer Plus. 2015; 4:703.

10. Kon K, Shiota M, Sakuyama A, Ozeki M, Kozuma W, Kawakami S, Kasugai Sh.Evaluation of the Alteration of Occlusal Distribution in Unilateral Free-End and Intermediate Missing Cases. J Oral Implantology 2017; 43:3-7.

11. Daftary F, Mahallati R, Bahat O, Sullivan RM. Lifelong craniofacial growth and the implications for osseointegrated implants. Int J Oral Maxillofac Implants 2013; 28:163-9.

12. Junior FAA, Tiossi R, Macedo AP, Mattos MGCh, Ribeiro RF, Rodrigues RCS. Importance of a distal proximal contact on load transfer by implant-supported single adjacent crowns in posterior region of the mandible: a photoelastic study. J Appl Oral Sci. 2013; 21:397-402 